\title{
Resistance against white spot syndrome virus (WSSV) infection in wild marine crab Gaetice depressus by injection of recombinant VP28 protein
}

\author{
Chun Soo Kim*, Seung Hyuk Choi, Min Sun Kim and Ki Hong Kim ${ }^{\dagger}$ \\ "Food Standard Division, Ministry of Food and Drug Safety, Chungbuk 363-700, Korea \\ Department of Aquatic Life Medicine, Pukyong National University, Pusan 608-737, Korea
}

\begin{abstract}
The resistance against white spot syndrome virus (WSSV) infection in wild marine crab Gaetice depressus by the immunization of a recombinant glutathione-S-transferase (GST) fused VP28 protein (GST-VP28) was evaluated. The cumulative mortalities of GST-VP28 injected groups were lower than those of the control groups at 10 days of post-challenge, and the time to death of $50 \%$ crab $\left(\mathrm{TD}_{50}\right)$ was delayed by the immunization using GST-VP28. The group boosted with GST-VP28 after 2 weeks of primary immunization clearly showed longer $\mathrm{TD}_{50}$ than non-boosted group against challenge with WSSV. This result suggests that boosting with the antigen protein elicit stronger immune responses similar to adaptive immune responses of vertebrates. However, the short $\mathrm{TD}_{50}$ was observed in the group challenged at 3 weeks post boosting comparing to the group challenged at 1 week post boosting. This suggests that the protective strength of immunization decreased by the time.
\end{abstract}

Key words: Gaetice depressus, White spot syndrome virus, Immunization, GST-VP28

White spot syndrome virus (WSSV) is the causative agent of a devastating viral disease in aquatic organisms, particularly in cultured penaeid shrimp. Since the initial discovery of the virus in farmed penaeid shrimp in Taiwan (Chou et al., 1995) and first isolation from Penaeus japonicus in Japan in 1993 (Inouye et al., 1994), it has rapidly spread to shrimp farms in many countries in Asia, Indo-Pacific and Western hemisphere, and caused a major impact on the economy of the shrimp farming industry in South-east Asia (Flegel, 1997).

It has been assumed that invertebrates lack an adaptive immune system and rely solely on innate immune responses (Kimbrell and Beutler, 2001). However, a

${ }^{\dagger}$ Corresponding author: Ki Hong Kim

Tel: 82-51-629-5943; Fax: 82-51-629-5938

E-mail: khkim@pknu.ac.kr recent study on the line-specific memory of the defense system in an invertebrate host, the copepod Macrocyclops albidus, against a natural parasite, the tapeworm Schistocephalus solidus, showed that the success of reinfection depends on the antigenic resemblance between the consecutively encountered parasites indicating the possibility of specific memory in an invertebrate defense system (Kurtz and Franz, 2003). The effective protection of Penaeus spp. (shrimp) against vibriosis with a formalin-killed Vibrio spp. vaccine supplemented with ß-1,3-glucan has been reported (Alabi et al., 1999; Itami et al., 1989; Kou et al., 1989; Teunissen et al., 1998). In addition, Venegas et al. (2000) reported that Penaeus japonicus survived from experimental or natural infection of WSSV revealed more potential to resist the virus infection, which may also suggest the possible enhancement of an adaptive immune-like system 
(quasi-immune response) after exposure to WSSV. Recent studies have also demonstarted that the resistance of the penaeids against WSSV could be enhanced by the immunization with WSSV envelop proteins (Namikoshi et al., 2004; Satoh et al., 2009, 2010; Syed and Kwang, 2011; Witteveldt et al., 2004a,b; Yang et al., 2012), which suggests the presence of adaptive or specifically inducible immune responses in shrimp and consequently opens a new promising way to control WSSV.

WSSV can infect a wide range of arthropods including several species of penaeid prawns (Corsin et al., 2001; Lu et al., 1997), crabs (Chen et al., 2000; Sahul Hameed et al., 2002), fresh water crayfish (Huang et al., 2001; Jiravanichpaisal et al., 2001) and Artemia (Li et al., 2003). Previously, Gaetice depressus (Decapoda), a crab species commonly found along the coastal areas of the Korean peninsula, has been known to be highly susceptible to WSSV (Kim and Kim, 2004). Due to the difficulty of getting penaeids in winter season in Korea, G. depressus was used as an alternative host for WSSV experiments. Therefore, in the present study, the wild crabs ( $G$. depressus) were used to evaluate the induction of the resistance against WSSV by immunizing with a recombinant glutathione-S-transferase (GST) fused VP28 protein that is a major structural envelope protein of WSSV and involved in the systemic infection of shrimp (van Hulten et al., 2001).

\section{Materials and Methods}

\section{Crabs}

Wild marine crab, G. depressus (3-4 g body weight) were collected from the Dong-Baek island of Busan. After the acclimation for 2 weeks, 10 crabs were randomly selected and WSSV infection was screened using the PCR primers (forward primer: 5'-GGGAATTCATGGAATTTGGCAACCTAAC-3' and reverse primer: 5'-GGTCGACCTTTACTTCTTGATTTCGTCC-3'), which amplify a 650 bp frag- ment of VP28 gene in WSSV. Randomly sampled 10 crabs were verified free of any natural WSSV infection before immunization experiments. No mortality was recorded in experimental and control groups before challenge test with WSSV. Crab in the experimental tanks was placed in individual small cages to prevent cannibalism. During acclimation and experimental periods, crabs were fed with minced marine fish muscle. The water temperature and salinity were adjusted to $26 \pm 1^{\circ} \mathrm{C}$ and $33 \%$, respectively.

\section{Preparation of viral inoculum}

Deep-freezed Penaeus chinensis, succumbed by the WSSV infection was thawed and muscle tissue was ground using a homogenizer (ART-Moderne Labortechnik, Germany) in 10-fold volume of sterile phosphate buffered saline (PBS) at $4{ }^{\circ} \mathrm{C}$ and centrifuged at $12,000 \times \mathrm{g}$ for $10 \mathrm{~min}$ at $4^{\circ} \mathrm{C}$. The supernatant was filtered through a $0.45 \mu \mathrm{m}$ membrane and used WSSV challenge experiments.

\section{Recombinant VP28 protein production}

PCR was utilized to amplify the open reading frame of the VP28 using the forward primer (VPexp28F 5'-GGAATTCATGGATCTTTCTTTCACTCTTTC-3') and reverse primer (VPexp28R 5'AGTCGACATTTACTCGGTCTCAGTGCC-3') with a EcoRI and a Sall restriction site, respectively. The resulting fragment was cloned into pGEM-T vector (Promega, WI, USA) and then subcloned into in the EcoRI and Sall sites of the pGEX/4T-1 vector (Amersham Biosciences, NJ, USA). The recombinant VP28 was expressed in E. coli BL21 (DE3) as a fusion protein with glutathione S-transferase (GST), and the resulting fusion protein (GST-VP28) was purified according to the manufacturer's instructions using gluthatione-sepharose 4B columns (Amersham Biosciences). The resulting E. coli expression samples and the purified proteins were analysed by SDSPAGE and the protein concentration was determined using the BCA protein assay (Sigma, MO, USA). 


\section{Immunization experiments}

The crabs were divided into 4 experimental groups of 20 crabs, and 4 control groups of 20 crabs corresponding to each experimental group. For the immunization experiments, the purified GST-fused VP28 protein $(250 \mu \mathrm{g} / \mathrm{crab})$ was injected intramuscularly to the first experimental group (V-I), and the V-I group was challenged by intramuscular injection of the WSSV solution at a dose of $50 \mu \mathrm{l} / \mathrm{crab}$ at 1 week after the immunization. The 2nd (V-II) and the 3rd (V-III) groups were boosted by injecting the same amount of the protein at 2 weeks after the initial immunization, and challenged by injection of WSSV dilution at 1 week or 3 weeks after the boost, respectively. The crabs in the 4th group (V-IV) were injected with the same amount of the purified GST protein and were challenged at 1 week after the injection. As a negative control group, 4 control groups of each experimental group were injected PBS and were manipulated as the same regime with each corresponding experimental group. Mortality was recorded twice a day, and dead crab were tested for the presence of WSSV by PCR.

\section{Results}

Bands corresponding to GST fused VP28 (GST-
VP28) and non-fused GST proteins expressed in $E$. coli (Fig. 1A, lane 2 and Fig. 1B, lane 2), and the purified proteins by affinity chromatography (Fig. 1A, lane 1 and Fig. 1B, lane 1) were observed at the expected molecular weights. This indicates that the fused VP28 protein was correctly expressed in E. coli expression system. The purified VP28 was used for the immunization experiments.

Cumulative mortalities of all the control groups exceeded $90 \%$ at 10 days post-challenge, while the cumulative mortalities of crabs injected with GST-VP28 were $70 \%$ in V-I group, $40 \%$ in V-II group and $55 \%$ in V-III group (Fig. 2). The time to death of $50 \%$ crabs $\left(\mathrm{TD}_{50}\right)$ for GST-VP28 injected experimental groups was clearly longer than that of PBS injected control groups. However, injection of purified GST (V-IV group) had no effect on the mortality and $\mathrm{TD}_{50}$ when compared to its control group. All dead crabs were positive for WSSV by PCR diagnostics as described above.

\section{Discussion}

In the present study, the cumulative mortalities of GST-VP28 injected groups were lower than those of each corresponding control group, and the time to
(A)

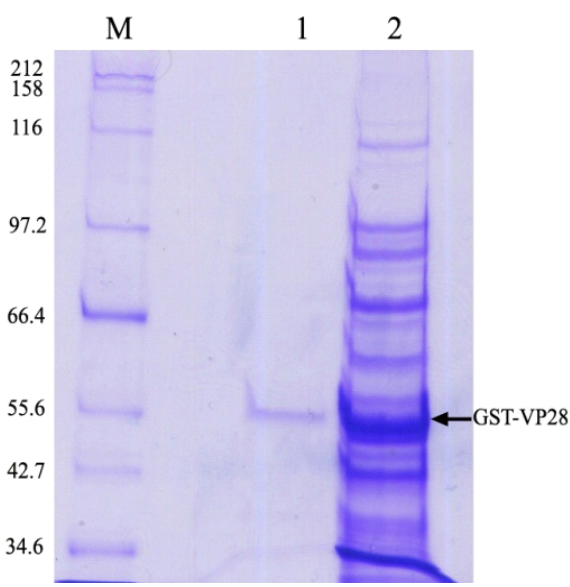

(B)

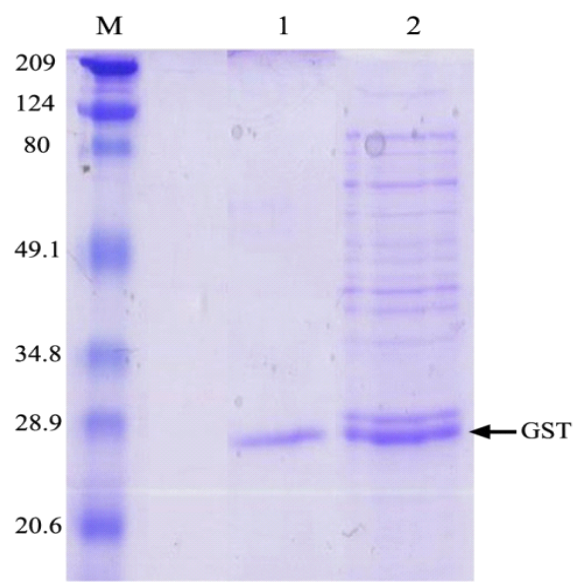

Fig. 1. Coomassie blue stained SDS-PAGE gel of GST-VP28 (A) and GST (B) expressed in E. coli. M: protein molecular mass marker (kDa), lane 1: purified GST-VP28 (A) and GST (B), lane 2: total GST-VP28 (A) and GST (B). 


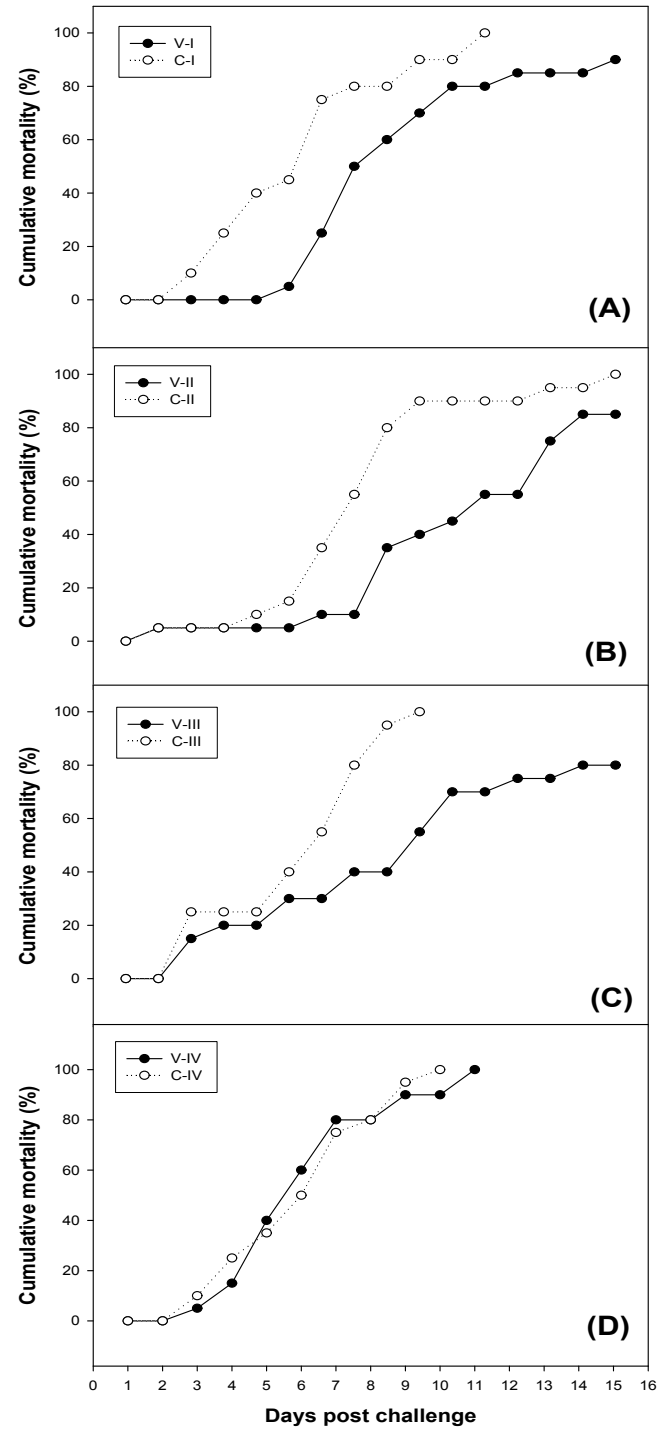

Fig. 2. The cumulative mortality of WSSV-infected crap groups: (A) group V-I was injected intramuscularly the purified GST-VP28 protein, and challenged by the injection of WSSV 1 week after the immunization; (B) $\mathrm{V}-\mathrm{II}$ and (C) V-III groups were boosted by injecting GST-VP28 protein at 2 weeks after the initial immunization, and were challenged by injection of WSSV at 1 week (V-II) or 3 weeks (V-III) after the boost; (D) V-IV group was injected intramuscularly the purified GST protein, and was challenged by the injection of WSSV 1 week after the immunization. Control groups C-I, C-II, $\mathrm{C}-\mathrm{III}$ and C-IV were PBS injected and were manipulated as the same regime with each corresponding experimental group. death of $50 \%$ crab $\left(\mathrm{TD}_{50}\right)$ was clearly lengthened by the immunization with GST-VP28. VP28, the identified WSSV envelope proteins, was found to be involved in the systemic infection of WSSV into shrimp and its polyclonal antiserum was capable to neutralize the virus infection (van Hulten et al., 2001). Several studies have demonstrated the protection of shrimp against WSSV by intramuscular injection of purified recombinant VP28 (Namikoshi et al., 2004; Witteveldt et al., 2004a), or oral administration of inactivated E. coli containing expressed VP28 in inclusion bodies or recombinantly produced VP28 protein (Witteveldt et al., 2004b; Satoh et al., 2009, 2010). The present study firstly demonstrated that the resistance of marine wild crab, G. depressus, against WSSV infection could be enhanced by the immunization with VP28.

Rojtinnakorn et al. (2002) reported that haemocytes of $P$. japonicus infected with WSSV expressed defense-related genes such as protease inhibitors, apoptotic peptides and tumor-related proteins. Roux et al. (2002) and Dhar et al. (2003) reported the up-regulation of lipopolysaccharide and B-1,3-glucan binding protein (LGBP) gene and hemocyanin gene in WSSV-infected P. stylirostris, respectively. Recently, Zhang et al. (2004) showed that the hemocyanin isolated from $P$. monodon was broadly antiviral against a variety of DNA and RNA viruses. Therefore, it cannot be excluded that those nonspecific antiviral proteins or peptides might be activated by the injection of GST-VP28 in crabs. Witteveldt et al. (2004b) showed that injection of shrimp with non-fused maltose-binding protein resulted in a small positive effect on shrimp survival when challenged two days after the booster. However, we could not observe any positive effects of non-fused GST on the resistance of crab against WSSV challenge, suggesting that the resistance of crab against WSSV in the present study be enhanced by VP28 but not GST.

In the present results, the groups boosted with GST-VP28 at 2 weeks after primary immunization 
showed clearly longer $\mathrm{TD}_{50}$ than the group immunized only once with GST-VP28. This result suggests that repeated boosting $G$. depressus with a same antigen elicit immune responses stronger than primary immunization which is similar to adaptive immune responses of vertebrates. However, the fact that the $\mathrm{TD}_{50}$ in the group challenged at 3 weeks post boosting was shorter than that in the group challenged at 1 week post boosting indicates that the protective strength of immunization might be diminished by the time.

\section{References}

Alabi, A.O., Jones, D.A. and Latchford, J.W.: The efficacy of immersion as opposed to oral vaccination of Penaeus indicus larvae against Vibrio harveyi. Aquaculture, 178: 1-11, 1999.

Chen, L.L., Lo, C.F., Chiu, Y.L., Chang, C.F. and Kou, G.H.: Natural and experimental infection of white spot syndrome virus (WSSV) in benthic larvae of mud crab Scylla serrata. Dis. Aquat. Org., 40: 157$161,2000$.

Chou, H.Y., Huang, C.Y., Wang, C.H., Chiang, H.C. and Lo, C.F.: Pathogenicity of a baculovirus infection causing white spot syndrome in cultured penaeid shrimp in Taiwan. Dis. Aquat. Org., 23:165-173, 1995.

Corsin, F., Turnbull, J.F., Hao, N.V., Mohan, C.V., Phi, T.T., Phuoc, L.H., Tinh, N.T. and Morgan K.L.: Risk factors associated with white spot syndrome virus infection in a Vietnamese rice-shrimp farming system. Dis. Aquat., Org. 47:1-12, 2001.

Flegel, T.W.: Special topic review: major viral diseases of the black tiger prawn (Penaeus monodon) in Thailand. World J. Microbiol. Biotechnol., 13: 433442, 1997.

Huang, C.H., Zhang, L.R., Zhang, J.H., Xiao, L.C., Wu, Q.J., Chen, D.H. and Li. J.K.K.: Purification and characterization of white spot syndrome virus (WSSV) produced in an alternate host: crayfish, Cambarus clarkii. Virus Res.. 76: 115-125, 2001. Inouye, K., Miwa, S., Oseko, N., Makaro, H., Kimura, T., Momoyama, K. and Hiraoka, K.: Mass mortality of cultured kuruma shrimp Marsupenaeus japanicus in Japan in 1993: electron microscopic evidence of the causative virus. Fish Pathol., 9: 149-158, 1994. Itami, T., Takahashi, Y. and Nakamura, Y.: Efficacy of vaccination against vibriosis in cultured kuruma prawns Penaeus japonicus. J. Aquatic Anim. Health 1: 234-242, 1989.

Jiravanichpaisal, P., Bangyeekhun, E., Soderhall, K. and Soderhall, I.: Experimental infection of white spot syndrome virus in freshwater crayfish Pacifastacus leniusculus. Dis. Aquat. Org., 47: 151-157, 2001.

Kim, C.S. and Kim, K.H.: Experimental infection of white spot syndrome virus (WSSV) in wild crab, Gaetice depressus. J. Fish Pathol., 17: 213-216, 2004.

Kimbrell, D.A. and Beutler, B.: The evolution and genetics of innate immunity. Nat. Rev. Gen., 2: 256-267, 2001.

Kou, G.H., Chen, S.N. and Huang, S.L.: Studies on bacterial infection and vaccination trials for culture Penaeus monodon in Taiwan. Diseases of Fish and Shellfish, Abstract of the 4th EAFP International Conference, 24-28 September 1989, Santiago de Compostela, Spain, p. 94, 1989.

Kurtz, J. and Franz, K.: Innate defence: evidence for memory in invertebrate immunity. Nature, 425: $37-$ 38, 2003.

Li, Q., Zhang, J., Chen, Y. and Yang, F.: White spot syndrome virus (WSSV) infectivity for Artemia at different developmental stages. Dis. Aquat. Org., 57: 261-264, 2003.

Lu, Y., Tapay, L.M., Gose, R.B., Brock, J.A. and Loh, P.C.: Infectivity of Yellow-head virus (YHV) and the Chinese baculolike virus (CBV) in two species of penaeid shrimp, Penaeus stylirostris (Stimpson) and P. vannamei (Boone). In: Flegel TW and MacRae I (eds) Diseases in Asian aquaculture III. Asian Fisheries Society, Manila, 1997.

Namikoshi, A., Wu, J.L., Yamashita, T., Nishizawa, T., Nishioka, T., Arimoto, M. and Muroga, K.: Vaccination trials with Penaeus japonicus to induce resistance to white spot syndrome virus. Aquaculture, 229: 25-35, 2004.

Rojtinnakorn, J., Hirono, I., Itami, T., Takahashi, Y. and Aoki, T.: Gene expression in haemocytes of kuruma prawn, Penaeus japonicus, in response to infection with WSSV by EST approach. Fish Shellfish Immunol., 13: 69-83, 2002.

Roux, M.M., Pain, A., Klimpel, K.R. and Dhar, A.K.: The lipopolysaccharide and B-1,3-glucan binding 
protein gene is upregulated in white spot virus-infected shrimp (Penaeus stylirostris). J. Virol., 76: 7140-7149, 2002.

Sahul Hameed, A.S., Yoganandhan, K., Sathish, S., Rasheed, M., Murugan, V. and Jayaraman, M.: White spot syndrome virus (WSSV) in two species of freshwater crabs (Paratelphusa hydrodomous and P. pulvinata). Aquaculture, 201:179-186, 2001.

Satoh, J., Nishizawa, T. and Yoshimizu, M.: Duration and booster effect of phylactic response against white spot syndrome virus infection in kuruma shrimp orally administrated with recombinant viral proteins, rVP26 and rVP28. Fish Pathol., 44: 120127.

Satoh, J., Kim, H.J., Matsui, T. and Nishizawa, T.: Optimization of WSSV rVP expression in E. coli cells and minimum dose of rVPs for oral vaccination in kuruma shrimp. Fish Pathol., 45: 169-174, 2010.

Syed, M.S. and Kwang, J.: Oral vaccination of baculovirus-expressed VP28 displays enhanced protection against white spot syndrome virus in Penaeus monodon. PLoS One, 6: e26428, 2011.

Teunissen, O.S.P. Faber, R., Booms, G.H.R., Latscha, T. and Boon, J.H.: Influence of vaccination on vibriosis resistance of the giant black tiger shrimp Penaeus monodon (Fabricius). Aquaculture, 164: 359-366, 1998. van Hulten, M.C.W., Witteveldt, J., Snippe, M. and Vlak, J.M.: White spot syndrome virus envelope protein VP28 is involved in the systemic infection of shrimp. Virology, 285: 228-233, 2001.

Venegas, C.A., Nonaka, L., Mushiake, K., Nishizawa, T. and Muroga, K.: Quasi-immune response of Penaeus japonicus to penaeid rod-shaped DNA virus (PRDV). Dis. Aquat. Org., 42: 83-89, 2000.

Witteveldt, J., Vlak, J.M. and van Hulten, M.C.W.: Protection of Penaeus monodon against white spot syndrome virus using a WSSV subunit vaccine. Fish Shellfish Immunol., 16: 571-579, 2004a.

Witteveldt, J., Cifuentes, C.C., Vlak, J.M., van Hulten, M.C.W.: Protection of Penaeus monodon against white spot syndrome virus by oral vaccination. J. Virol., 78: 2057-2061, 2004b.

Yang, J.Y., Chang, C.I., Liu, K.F., Hseu, J.R., Chen, L.H. and Tsai, J.M.: Viral resistance and immune responses of the shrimp Litopenaeus vannamei vaccinated by two WSSV structural proteins. Immunol. Lett., 148: 41-48, 2012.

Zhang, X., Huang, C. and Qin, Q.: Antiviral properties of hemocyanin isolated from shrimp Penaeus monodon. Antiviral. Res., 61: 93-99, 2004.

Manuscript Received : February 14, 2014

Revised : April 10, 2014

Accepted: April 11, 2014 